\title{
PROJETO ECSIC - "ESCOLA, CONECTIVIDADE E SOCIEDADE DA INFORMAÇÃO E DO CONHECIMENTO”
}

\author{
Basso, Marcus Vinicius* \\ Nevado, Rosane A.** \\ Fagundes, Léa ${ }^{* * *}$
}

\section{RESUMO}

O projeto ECSIC estuda e experimenta as condições e os recursos que tornem possível as mudanças na Escola pública da periferia urbana para promover a inclusão digital do alunado numa sociedade em rede. Ele se desenvolve apoiado por convênio entre a UFRGS, a Prefeitura de Porto Alegre e o BNDES dentro da Linha Programática Atenção Integral ao Adolescente e ao Jovem. Visa disseminar na Rede Municipal de Ensino os protótipos desenvolvidos no LEC/UFRGS para apropriação das novas tecnologias digitais, seus impactos e as mudanças.

PALAVRAS CHAVE: inclusão digital, conhecimento, tecnologias da Informação e da Comunicação, Formação de Recursos Humanos.

\section{ABSTRACT}

The ECSIC project studies the context, human resources, tools and methodologies to make possible changes to overcome the digital divide in the public schools on the urban marginal regions. This project is funded by the BNDES throught a partnership between the government of Porto Alegre and the local federal university (UFRGS) following the Program of Integral Attention to the Youth. The goal in sight is to disseminate new models developed in LEC/UFRGS to introduce IT in the K14 curriculum.

KEYWORDS: digital inclusion, knowledge, technologies of the Information and the Communication, Formation of Human Resources.

\section{O PROBLEMA}

Como introduzir as novas tecnologias da Informação e da Comunicação na Escola Pública para promover o desenvolvimento do Cidadão da Sociedade do Conhecimento que possa também se tornar agente de Desenvolvimento Econômico e Social?

Tabela 1: Escolas da Rede Municipal de Ensino participantes do Programa ECSIC

\begin{tabular}{|c|c|c|}
\hline região & número de escolas & $\begin{array}{c}\text { data de entrada no } \\
\text { projeto }\end{array}$ \\
\hline Extremo Sul & 5 & Janeiro de 2003 \\
\hline & 1 & Março de 2003 \\
\hline $\begin{array}{c}\text { Gloria/Cruzeiro/Cristal/ } \\
\text { Centro Sul }\end{array}$ & 3 & Janeiro de 2003 \\
\hline & 1 & Julho de 2003 \\
\hline
\end{tabular}

\footnotetext{
* Professor Adjunto do Instituto de Matemática da UFRGS, Vice-diretor do CINTED, Pesquisador do Laboratório de Estudos Cognitivos (LEC/UFRGS), Doutor em Informática na Educação. E-mail: mbasso@psico.ufrgs.br

** Professor Adjunto da Faculdade de Educação da UFRGS, Pesquisadora do Programa de Pós-Graduação em Educação (PPGEDU), Chefe Substituto do Departamento de Estudos Básicos da Faculdade de Educação, Pesquisadora do Laboratório de Estudos Cognitivos da (LEC/UFRGS), Doutor em Informática na Educação. E-mail : rosane@edu.ufrgs.br

*** Professor Titular (aposentada) do Instituto de Psicologia, Professor Convidado do Instituto de Psicologia, Docente do PGIE, Coordenadora de Pesquisa do Laboratório de Estudos Cognitivos, Doutor em psicologia. E-mail: leafagundes@ vortex.ufrgs.br
} 


\begin{tabular}{|c|c|c|}
\hline região & número de escolas & $\begin{array}{c}\text { data de entrada no } \\
\text { projeto }\end{array}$ \\
\hline & 1 & Agosto de 2003 \\
\hline Leste & 4 & Janeiro de 2003 \\
\hline Noroeste & 1 & Julho de 2003 \\
\hline Norte & 1 & Janeiro de 2003 \\
\hline & 1 & Janeiro de 2003 \\
\hline & 2 & Março de 2003 \\
\hline Partenon/Lomba do Pinheiro & 2 & Junho de 2003 \\
\hline & 1 & Março de 2003 \\
\hline & 2 & Julho de 2003 \\
\hline
\end{tabular}

Na tabela acima, observe-se que há diferentes momentos de ingresso das escolas no projeto. Isto se deve à orientação que seguimos de primeiro sensibilizar a comunidade de cada escola respeitando seus tempos. Não deve haver coação sobre os professores, mas conquista e parceria.

\section{OBJETIVOS}

1 Oferecer acesso e suporte a novos usos das TIC's para as comunidades das escolas públicas da periferia urbana de Porto Alegre, que vem sendo excluídas das sociedades letradas, de modo que se tornem autores e pratiquem a comunicação cooperativa e solidária,

2 Organizar contextos e recursos para os usos dessas tecnologias de modo que os alunos melhorem a qualidade da aprendizagem e desenvolvam novas habilidades e competências para a cidadania e qualificação para a participação social produtiva;

3 Qualificar os professores e educadores do sistema de ensino para incorporar os recursos da TIC's nas suas práticas educativas, visando a apropriação pessoal e coletiva dos recursos tecnológicos, analisando e avaliando a adequação do seu uso para a melhoria da aprendizagem.

4 Formar recursos humanos, no âmbito da universidade, visando a melhoria da qualificação dos futuros professores para o uso das TIC'as na educação.

\section{METAS REFERENTES AOS OBJETIVOS}

1 Pesquisa, desenvolvimento, testagem e validação do uso de software, ferramentas de comunicação e ferramentas pedagógicas que facilitem a aprendizagem dos alunos.

2 Novos usos das tecnologias, substituindo a utilização limitada a jogos eletrônicos, passando a incorporar essas tecnologias a práticas interativas e construtivistas. Na sala de aula essas TICs contextualizarão os ambientes de vida dessas comunidades, enriquecendo a sala de aula com novos materiais, riqueza de informações e maior facilidade para comunicação.

3. Qualificação técnico-pedagógica de professores e educadores de cada uma das escolas envolvidas no projeto e de assessores da SMED.

4 Formação continuada e em serviço de estudantes da universidade para o uso das TIC'S, visando a melhoria da qualificação dos futuros professores.

\section{AÇÕES ESTRATÉGICAS}


Estão sendo desenvolvidas as seguintes ações estratégicas:

5.1 Construção/adaptação de ambientes virtuais para incluir as comunidade de aprendizagem em diferentes tempos conectando os espaços em múltiplos sistemas:

\subsubsection{Ambiente "Mimerdesk" - http://mimer.psico.ufrgs.br}

Adaptação do ambiente desenvolvido pela comunidade de software livre para servir à documentação do processo de desenvolvimento do projeto. Como suporte para interação entre docentes e monitores, destinado ao acompanhamento e orientação de seus estudos e atividades, supervisão a distância, planejamento, registro e documentação das atividades diárias de cada integrante da equipe de recursos humanos por escola; o ambiente está se constituindo em repositório de diferentes tipos de informações, dados sobre os resultados alcançados, trocas de textos científicos, software, hiperdocumentos, projetos cadastrados, imagens, fotos, vídeos, etc...

\subsection{2 "Amadis - ESCOLA" - http://escola.psico.ufrgs.br}

Planejamento, construção e testagem de espaços para suporte da conexão entre as escolas, cadastramento de e-mail, interação e discussão das atividades desenvolvidas pelos alunos das diversas escolas integrantes do projeto,informações, ferramentas, recursos multimídia, publicação das produções dos alunos, interação on-line. O. Amadis - ESCOLA é um ambiente que se constitui das seguintes ferramentas: (1) Chat; (2) WebMail; (3) Hospedagem de páginas; (4) Publicação por FTP. Este é um ambiente com visual claro para as crianças usarem durante o seu processo de aprendizagem. Tendo como finalidade proporcionar conexão entre as escolas, nele é possível que as crianças comuniquem-se e discutam os seus projetos orientadas por seus professores orientadores, com o bom uso das ferramentas disponíveis.

\subsubsection{Ambiente AMADIS - http://amadis.psico.ufrgs.br}

Planejamento, construção, testagem e desenvolvimento continuado de suporte para a formação de professores em serviço, enfatizando o desenvolvimento de projetos. O AMADIS é um ambiente que oferece recursos de cadastramento, trocas cooperativas, coleta de dados, experiências com os dados coletados para o desenvolvimento e a publicação de projetos de aprendizagem. Neste ambiente, individualmente ou em equipes os professores-alunos elaboram e desenvolvem suas propostas utilizando-se de recursos de comunicação síncrona e assíncrona, como webmail, chats, foruns, diários, webfolios, podendo ainda complementar os estudos sobre os fundamentos teóricos e tecnológicos com seminários e oficinas sistemáticos, sob a supervisão de seu docente orientador.

\subsection{Equipes de Pesquisadores e Monitores}

Foram constituídas equipes por escola formadas por um pesquisador-orientador e quatro monitores, dois deles em cada turno:

- a constituição da equipe de monitores de cada escola é de dois estudantes de escola técnica e dois estudantes de graduação ou mestrado;

- a constituição do grupo de pesquisadores é de doutores e mestres doutorandos.

\subsection{Dinâmica do Projeto na Escola}

Foram atendidas, de janeiro a dezembro de 2003, 25 escolas, sendo que algumas iniciaram suas atividades nos meses de março, junho ou agosto, conforme dados apresentados na tabela 1 . 
O Projeto começou em cada escola pelo contato do pesquisador que coordena a equipe de monitores/bolsistas com elementos da equipe diretiva, visando a construção de uma relação de parceria e confiança. Em visitas periódicas, o projeto foi apresentado a direção, coordenação pedagógica, professores e Comissão de Informática da escola.

Os monitores têm sido recebidos no ambiente de informática, onde cumprem um turno de trabalho realizando múltiplas atividades de apoio tanto pedagógico, quanto tecnológico aos professores e seus grupos de alunos. Essas atividades são desenvolvidas no respectivo turno da aula regular dos alunos. As produções individuais ou de pequenos grupos de alunos são publicadas na Internet mediante a utilização dos ambientes digitais e de suas ferramentas.

Os pesquisadores são os docentes que atendem o curso a distância e em serviço, no ambiente virtual AMADIS. Além disso, os pesquisadores orientam a formação continuada dos monitores, seja ela realizada presencialmente ou a distância. A figura 1 representa a dinâmica de interação proposta para o trabalho cooperativo entre pesquisadores e monitores da UFRGS, Equipes Diretivas e Professores das Escolas e Assessoria da SMED.

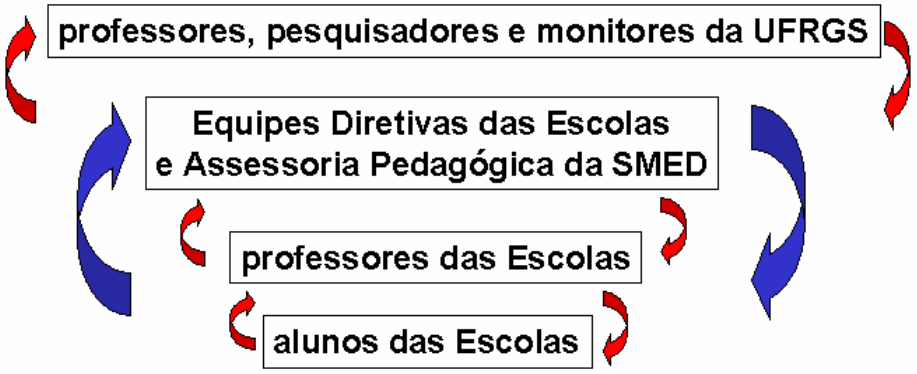

Figura 1: dinâmica de trabalho realizada no projeto

\subsection{Suporte Tecnológico:}

Uma equipe de programadores permanece desenvolvendo novos recursos de software, monitorando e gerenciando os ambientes, administrando recursos dos sistemas e das contas dos usuários; definindo regras de interação e uso da rede e elaborando planilhas para a coleta de dados sobre os experimentos.

\section{RESULTADOS}

\subsection{A Formação e o Treinamento dos Bolsistas}

A equipe de pesquisadores e docentes do LEC dedica-se à formação e treinamento dos monitores para as funções de apoio aos professores nas Escolas. Cada escola recebe equipes de monitores bolsistas nos dois turnos - manhã e tarde. Essas equipes são também interdisciplinares formadas por estudantes de Escolas Técnicas e por estudantes das diferentes licenciaturas, com ênfase na Licenciatura em Matemática porque em nossa UFRGS se realiza uma experiência inovadora que introduz a informática na formação dos futuros professores de Matemática. Também incluímos estudantes de Psicologia que se apropriam do "método clínico" piagetiano, dos fundamentos do construtivismo e dos estudos sobre aquisição da língua escrita numa perspectiva psicogenética.

Mas a equipe de bolsistas de cada escola recebe a orientação de um pesquisador do LEC, por interação no ambiente digital a distância de forma síncrona e assíncrona e por interação presencial sendo que o orientador do LEC faz visitas semanais, ou mais freqüentes conforme o caso, para assessorar tantos os bolsistas in loco como os 
professores e gestores na escola.

A formação dos bolsistas considerou a proposta deste modelo de informática na educação: toda a prática se constitui em atividade fundamental para a reflexão crítica de seus fundamentos. Assim os treinamentos no uso de técnicas devem ocorrer em situações de aprendizagem do próprio bolsista com alunos na escola. O bolsista precisa aprender "fazendo" e refletindo sobre seus procedimentos, para aprender a "pensar", também registrando, publicando e interagindo com seus pares, buscando trocas de modo cooperativo e enriquecedor. Este esforço se dirige à busca de perspectivas diferentes para o mesmo problema assim como de soluções criativas para diferentes problemas.

Os resultados dessa formação em serviço, reflexos da aprendizagem e da aplicação prática do uso da tecnologia aparecem tanto nos documentos publicados pelos bolsistas em formação quanto na produção dos alunos em atendimento por eles e que podem ser encontradas nas páginas já publicadas, e consistem em;

1. cadastramento de todos os alunos no webmail do ambiente digital http://escola.psico.ufrgs.br realizado pelos próprios alunos com a orientação dos bolsistas. $\mathrm{O}$ resultado mais significativo nesta fase foi a escrita do nome e a escolha e escrita de senha que provocou o interesse para aprender a escrever seu nome completo e seu endereço por alunos que não sabiam fazê-lo. Muitos sequer conheciam seu próprio sobrenome;

2.trocas de mensagens no correio-eletrônico dentro da escola, mas também entre alunos de escolas diferentes;

3.elaboração de páginas e sua publicação no ambiente digital.

Participaram do Projeto 120 bolsistas de diversos cursos de graduação, conforme listados a seguir: Arquitetura, 02; Artes, 02, Ciências da computação, 03; Ciências Sociais, 01; Ciências Jurídicas. 02; Engenharia, 07; Filosofia, 02; Física, 02; Geografia, 04; Geologia, 01; História, 02; Letras, 12; Matemática, 46 ; Pedagogia, 7; Psicologia, 20; Química, 05.

\subsection{Formação de monitores nas escolas}

Com a finalidade de formar recursos humanos na própria escola que possam torná-la auto-suficiente quando terminar a subvenção do BNDES, resolvemos começar a construção de uma cultura de formação de monitores.

Aproveitamos a solicitação das escolas para oferecer introdução a informática para alunos dos anos finais da escolaridade e escolhemos alguns grupos propondo-lhes a formação para monitores. Essa prática foi estendida pelos bolsistas também para alunos menores. O modelo, sendo aprendido na prática e através de trocas cooperativas, facilita os processos de tomada de consciência, de metacognição. Dessa prática de monitoria por alunos da própria escola decorre a auto-sustentabilidade do projeto, além de serem criadas condições de atendimento individualizado com o recursos de seus próprios pares.

\subsection{Quadro - síntese de resultados}

Tabela 2: categorias e indicadores - metas atingidas 


\begin{tabular}{|c|c|c|c|c|}
\hline Categoria/Indicadores & meta & $\begin{array}{c}\text { Situação } \\
\text { em } \\
\text { Janeiro }\end{array}$ & $\begin{array}{c}\text { Situação em } \\
\text { dezembro }\end{array}$ & $\begin{array}{c}\% \\
\text { atingido }\end{array}$ \\
\hline \multicolumn{5}{|l|}{$\begin{array}{l}\text { 1. Conectividade - Apropriação da } \\
\text { tecnologia }\end{array}$} \\
\hline \multicolumn{5}{|l|}{1.1 webmail - cadastro } \\
\hline - Número de Professores & 280 & 0 & 609 & $217 \%$ \\
\hline - Número de Alunos & 7000 & 0 & 10500 & $150 \%$ \\
\hline $\begin{array}{l}\text {-Número Estudantes de graduação e } \\
\text { técnicos }\end{array}$ & 150 & 0 & 167 & $111 \%$ \\
\hline \multicolumn{5}{|l|}{$\begin{array}{l}1.2 \text { Uso de ferramentas na } \\
\text { comunicação }\end{array}$} \\
\hline - Número de Professores & 280 & 0 & 250 & $89 \%$ \\
\hline - Número de Alunos & 7000 & 0 & 5000 & $71 \%$ \\
\hline $\begin{array}{l}\text { - Número de Estudantes de } \\
\text { graduação e técnicos }\end{array}$ & 150 & 30 & 167 & $111 \%$ \\
\hline \multicolumn{5}{|l|}{$\begin{array}{l}\text { 2. Inovações na sala de aula com } \\
\text { uso da tecnologia }\end{array}$} \\
\hline \multicolumn{5}{|l|}{$\begin{array}{l}\text { 2.1 Ausência de Inovações - Treino } \\
\text { e prática no início do ano }\end{array}$} \\
\hline - Digitação de texto (cópia) & $0 \%$ & $85 \%$ & $5 \%$ & $95 \%$ \\
\hline - Jogos S-R & $0 \%$ & $100 \%$ & $5 \%$ & $95 \%$ \\
\hline \multicolumn{5}{|l|}{$\begin{array}{l}2.2 \text { Presença de Inovações no fim do } \\
\text { ano }\end{array}$} \\
\hline $\begin{array}{l}\text { - Jogos para alfabetização em língua } \\
\text { e matemática }\end{array}$ & $100 \%$ & $5 \%$ & $80 \%$ & $80 \%$ \\
\hline $\begin{array}{l}\text { - Leitura e produção de escrita - } \\
\text { autoria }\end{array}$ & $100 \%$ & $5 \%$ & $100 \%$ & $100 \%$ \\
\hline \multicolumn{4}{|l|}{ - Pesquisa incluindo web } & $95 \%$ \\
\hline - Solução de problemas & $100 \%$ & $0 \%$ & $60 \%$ & $60 \%$ \\
\hline - Trabalho cooperativo & $100 \%$ & $5 \%$ & $80 \%$ & $80 \%$ \\
\hline $\begin{array}{l}\text { - páginas publicadas por alunos na } \\
\text { web }\end{array}$ & - & - & 29616 & - \\
\hline $\begin{array}{l}\text { - páginas publicadas por professores } \\
\text { na web }\end{array}$ & - & - & 500 & - \\
\hline - trocas de mensagens diárias & - & - & 300 & - \\
\hline $\begin{array}{l}\text { - realização de chat (duração média } \\
-1 \mathrm{~h})\end{array}$ & - & - & $108 \mathrm{~h}$ & - \\
\hline - plantões de atendimento online & - & - & $1250 \mathrm{~h}$ & - \\
\hline \multicolumn{5}{|l|}{ 3. Sustentabilidade do projeto } \\
\hline $\begin{array}{l}\text { 3.1 Formação dos professores e } \\
\text { gestores }\end{array}$ & 280 & 0 & 250 & $89 \%$ \\
\hline - Seminários & - & - & $900 \mathrm{~h}$ & - \\
\hline - Oficinas & - & - & $900 \mathrm{~h}$ & - \\
\hline - reuniões de orientação nas Escolas & - & - & $600 \mathrm{~h}$ & - \\
\hline $\begin{array}{l}\text { - horas de trabalho dos orientadores } \\
\text { nas escolas }\end{array}$ & - & - & $4000 \mathrm{~h}$ & - \\
\hline
\end{tabular}


- apoio técnico aos professores para participação em eventos de divulgação científica - reuniões da Coordenação com gestores, professores das Escolas e assessoria pedagógica da SMED

- Planos de trabalho integrando tecnologias digitais no currículo 3.2 Formação de alunos-monitores das Escolas - práticas orientadas 3.3 Formação dos estudantes de graduação - número - Seminários

- Oficinas

- horas de trabalho nas Escolas

- orientação via Mimer Desk

3.4 Disponibilização dos recursos tecnológicos para a PMPA

4. Desenvolvimento de software produção de recursos tecnológicos para aprendizagem

4.1 Ambientes virtuais

4.2 Ferramentas para DataMining Mineração e recuperação de dados em Banco de Dados

4.3 Ferramentas para gerenciamento, publicação e acesso aos materiais e experiências pedagógicas

4.4 banco de dados

\begin{tabular}{|c|c|c|c|c|}
\hline & $\begin{array}{l}\text { funcional e } \\
\text { estável }\end{array}$ & & & \\
\hline \multicolumn{5}{|l|}{$\begin{array}{l}\text { 4.5 Ferramentas de comunicação } \\
\text { síncrona e assíncrona }\end{array}$} \\
\hline webmail & $\begin{array}{l}1 \text { ferramenta } \\
\text { funcional e } \\
\text { estável }\end{array}$ & 0 & 2 & $200 \%$ \\
\hline Chat & $\begin{array}{l}1 \text { ferramenta } \\
\text { funcional e } \\
\text { estável }\end{array}$ & 1 & 3 & $300 \%$ \\
\hline Fórum & $\begin{array}{l}1 \text { ferramenta } \\
\text { funcional e } \\
\text { estável }\end{array}$ & 1 & 2 & $200 \%$ \\
\hline Instant Message & $\begin{array}{l}1 \text { ferramenta } \\
\text { funcional e } \\
\text { estável }\end{array}$ & 0 & 2 & $200 \%$ \\
\hline
\end{tabular}


4.6 Jogos para alfabetização em língua e em matemática

\section{5 jogos funcionais e estáveis}

\section{DISCUSSÃO DOS RESULTADOS}

Ao concluir esta primeira fase do Projeto ECSIC, está disponível na Internet considerável acervo de dados para análise. O procedimento inicial consistiu em definir categorias de indicadores relacionados às metas. Num primeiro levantamento relacionamos objetivos/metas /ações /recursos usados/resultados alcançados. Este procedimento permitiu comparar quantitativamente os resultados esperados no início do ECSIC com os alcançados até o final do período desta primeira fase. Em continuidade serão processadas análises qualitativas que permitam explicar o comportamento dos indicadores e a consistência das relações estabelecidas entre eles. As condições de impacto, de sucesso serão buscadas, por ex., com questões como:

- Quais as condições que interferem quando se alcança um crescimento de $217 \%$ relativo ao cadastro de professores no webmail e de $150 \%$ relativo ao cadastro de alunos, mas o uso das conexões possíveis se expressa num percentual de $89 \%$ e $71 \%$ respectivamente?

- Já quanto a ausência de inovações, especificamente quanto a produção, textual apresenta um decréscimo de $95 \%$ e a presença de inovações apresenta um crescimento de $100 \%$, porque todos os alunos produziram e publicaram, individualmente ou em grupos textos próprios. O que resta investigar é a melhoria de qualidade dessa produção, para complementar o entendimento do impacto desses novos usos, por exemplo.

- Se esses primeiros 5000 alunos publicaram 29616 páginas na Internet com suas produções em diferentes níveis, quais são os fatores que devem ser tratados para que o trabalho cooperativo ultrapasse os $80 \%$ alcançados e os projetos desenvolvidos buscando a solução dos problemas propostos por eles os $60 \%$ ?

- Os recursos tecnológicos desenvolvidos pelas equipes evidenciam uma produção que se mantém entre 100 e $400 \%$. Que impactos podem ser esperados com a disponibilidade desses recursos para serem usados amplamente e com maior freqüência?

A importância dos resultados até agora alcançados reside na produção de mais conhecimento sobre as condições necessárias, suas facilidades, adequações, restrições, obstáculos a serem ultrapassados, etc... Finalmente, ante a vantagem do armazenamento em meio magnético, flexível e facilmente reutilizável os dados que são intrinsecamente complexos podem ser continuamente estudados e rearranjados em diferentes tratamentos lógico-matemáticos, podendo assim, serem exaustivamente analisados e servirem ao replanejamento e readequação. É o que se espera proceder na continuidade do Projeto.

\section{REFERÊNCIAS}

ARAGÓN DE NEVADO, R. Espaços Interativos de Construção de Possíveis: uma nova modalidade de formação de professores. Porto Alegre: PGIE/UFRGS, 2001. Tese de doutorado.

BASSO, M. V. E FAGUNDES, L. Informática Educativa e Comunidades de Aprendizagem. Em Azevedo e Outros. Identidade Social e a Construção do Conhecimento. Secretaria de Educação de Porto Alegre: Porto Alegre, 1997. 
BASSO, M.V.A. Espaços de Aprendizagem em Rede: novas orientações na formação de Professores de Matemática. Porto Alegre: PGIE/UFRGS, 2003. Tese de doutorado.

FAGUNDES, L. Projeto de Educação a Distância: Criação de Rede Informática para Alfabetização em Língua, Matemática e Tecnologia. (Enviado ao Cnpq), 1991.

http://p-ecsic.psico.ufrgs.br

INHELDER, B., BOVET, M. E SINCLAIR, H. Aprendizagem e Estruturas do Conhecimento. Saraiva: São Paulo, 1977.

PIAGET, J. Psicologia e Epistemologia. Para uma Teoria do Conhecimento. Publicações Dom Quixote: Lisboa, 1991.

PIAGET, J. A Eqüilibração das Estruturas Cognitivas - Problema Central do Desenvolvimento. Rio de Janeiro: Zahar Editores, 1976a.

PIAGET, J. Problemas Gerais da Investigação Interdisciplinar e Mecanismos Comuns. Bertrand: Lisboa, 1976

PIAGET, JEAN. Para Onde Vai a Educação? José Olympio Editora: Rio de Janeiro, 1984. 